tioularly important. The Sunday Times recntly ${ }^{1}$ publicized the case of a hospital nurse, Mrs. O'Neill, and the excrementally soiled lavatory walls of which she complained. It is remarkable that the hospital secretary should be reported to have stated, as it were in defence, that the walls remained soiled for eight days rather than the 18 days claimed by Mrs. O'Neill. It is even more extraordinary that the case should be said to draw "attention to the lack of any agreed procedure for disciplining nurses." What it should draw immediate attention to is the lack of any agreed procedure for cleaning hospitals.

Part of the trouble may lie in the Crown exclusion of N.H.S. hospitals from the province of the (public) Health Inspectorate. Can we not now open the hospital services to inspection by the health inspectors of the new local authorities?-I am, etc.,

MaIr Thomas Elizabeth Garrett Anderson Hospital, London N.W.1

1 Gillie, O., Sunday Times, 17 March, 1974, p. 6.

\section{Coping with Nose-bleeds}

SIR,-There is a surprising omission from your leading article ( 9 March, p. 405). The treatment of anterior epistaxis is adequately summarized, and even the use of an inflatable rubber bag in the nasal cavity is mentioned. However, posterior epistaxis, which is generally more profuse and constitutes a more serious problem in management, receives less attention. The only advice given to the general practitioner or casualty surgeon is to transfer the patient, presumably still bleeding profusely, to hospital for administration of a general anaesthetic. The use of a Foley catheter obviates the necessity for anaesthesia with the concomitant dangers of regurgitation of blood from the stomach and possible aspiration. The catheter can be easily inserted through the nasal cavity, even local anaesthesia being unnecessary, and inflated when it reaches the epipharynx. Gentle traction into the choanal opening produces an effective seal and prevents the swallowing or aspiration of blood. Transport and further management of the patient are thereby simplified and removal of his form of postnasal packing is easily performed and causes minimal patient disoomfort.-I am, etc.,

IAIN W. S. MAIR

Department of Otolaryngology, Sentralsykehuset,
Troms, Norway

SIR,-Epistaxis is a common problem, as your leading article states (9 March, p. 405) and in the middle-aged to elderly it is often difficult to control. In this group it is often impossible to detect a bleeding point in the accessible area of the nose. Nasad packing is not an easy operation and often badly done; it is certainly unpleasant and often distressing. For this reason I have used epsilon-aminocaproic acid or tranexamic acid by intravenous injection when the simple primary procedures of recumbency, sedation, and external compression have failed.

In my own experience of some dozens of such cases I can recall only one faillure and so was surprised at the brusque dismissal of this method in your leading article. I am sorry to be unable to give learned comment on the fibrinolytic activity of the nasal mucosa, but Rasmussen has done so. ${ }^{1}$ Nor do I feel competent to organize a satisfactory double-blind controlled trial in a busy accident and emergency department. It does, however, seem logical to employ an antifibrinolytic agent when bleeding is persistent, even in the absence of evidence of primary inhibition of fibrin formation, as it may have an effect on clot formation which in the circumstances is clearly inadequate for whatever reason. To argue that clotting cannot be enhanced by the use of an antifibrinolytic agent seems as iillogical as to contend that epistaxis is persistent because of the absence of a nasal pack.

In fact I am in the excellent company of many prostatic surgeons in finding epsilonaminocaproic acid an excellent haemostat in awkward circumstances.-I am, etc.,

R. H. HARDY

Accident and Emergency Departmen

General Hospital,
Hereford 1 Rasmussen, A. B., Acta Otolaryngologica, 1966,
61, 221.

SIR,-Concerning your leading article ( 9 March, p. 405) on the above subject, I feel that in view of the rather involved measures described I should write to you of my experience of nose-bleeding.

About 35 years ago as a houseman I was called to a medical ward to a patient who had nose-bleeding, and on my way I contemplated my previous rather ineffective experiences of packing the nose in such cases. When I arrived I was confronted by the very experienced, very senior ward sister who announced, "Whatever the cause there is only one treatment and it never fails." A cork about an inch long is placed between the upper and lower teeth to hold the mouth open and a wide bandage is wound around the head from the chin to the top of the head, where it is knotted. This maintains gentle pressure on the cork and as the mouth is thus held open the patient is obliged to breathe through the mouth and the clotting process is left undisturbed. The nose must not be blown or sniffed. It usually takes about 15 minutes. I have a high degree of confidenoe in this procedure which I have used and seen used many times during these many years and I hope its use might be the means of avoiding some of the more involved procedures described.-I am, etc.,

Tunworth, Hants

J. H. L. NEWNHAM

\section{Death during Dental Anaesthesia}

SIR,-I read with interest the comment made by Dr. J. G. Bourne (16 March, p. 516) on the case of a recent death during dental anaesthesia which was reported in your medicolegal column (2 February, p. 207). I should like to report a recent fatal case of severe unaccountable collapse following administration of anaesthesia in a dental chair.

A healthy child aged 10 needed dental extractions as he was suffering from an alveolar abscess and was in pain. He had developed chickenpox two days earlier. The child was instructed to take two $10 \mathrm{mg}$ trimeprazine tablets an hour before attending.

The child walked in to the dental surgery and was seated in the chair semi-upright $\left(45^{\circ}\right)$. He looked rather pale but at the time this was presumed to be due to the fact that he was in pain and had had a sleepless night. He was anaesthetized with $75 \%$ nitrous oxide, $25 \%$ oxygen, and $1.5 \%$ halothane. nitrous oxide, $25 \%$ oxygen, and $1.5 \%$ halothane. The concentration of halothane was later reduced
to $1.0 \%$. The respiration and colour of the child were monitored continuously and the pulse was felt intermittently. The dentist then removed the first four molar teeth. Both induction and extrac tion were quick and easy, together taking five minutes at the most. At the end of the procedure the child looked extremely pale and his pulse was slow and feeble. However, it was noted that we was not sweating. The chair was immediately he was not sweating. The chair was immediately
tilted right back so that the child was in about tilted right back so that the child was in about
$10^{\circ}$ head-down tilt and his legs were held up by a nurse. External cardiac compression was commenced and the lungs inflated rhythmically with oxygen. The child was taken to hospital, where he was treated for ventricular fibrillation but improvement was transient and he died $2 \frac{1}{2}$ hours after the collapse. Necropsy findings were negative.

It appears that the child had a vasovagal attack. In this case the hypotensive episode or cardiovascular collapse occurred without apparent cause or warning. Once peripheral vasodilation has begun and blood pressure is falling the sitting position will increase cerebral oligaemia by gravitational pooling of blood in the dependent portions of the body and will further lead to reduoed filling of the right atrium and cardiac output. There is no doubt that whatever the cause of hypotension its outcome in terms of brain damage or death of the patient is greatly influenced by the upright position traditionally used in dentistry. Though death during dental anaesthesia is rare, the difficulty in recognizing a vasovagal attack accounts for the fact that it occurs even with the most careful and experienced anaesthetists. Perhaps either by abandoning the sitting position or by adopting intensive monitoring while anaesthetizing patients in the dental chair one could avoid these occasional fatalities.-I am, etc.,

Anaesthetic Department,
Burnley General Hospital,

S. MEHTA Burnley, Lancs

\section{Central Nervous System Effects of Pentazocine}

SIR,-We were interested to note the findings of Dr. A. J. J. Wood and others (23 February, p. 305), who investigated the effects of pentazocine on the central nervous system. We also have noted hallucinations in patients who received pentazocine in the postoperative period. However, we have found that hallucinations in association with other analgesic drugs are not uncommon. In a study of patients in the postoperative period we have compared the incidence of hallucinations following the administration of pentazocine with that following morphine.

Patients admitted for elective general surgery were allocated randomly to two groups. For postoperative pain relief those in one group were given pentazocine $40-50$ mg intramuscularly and those in the other group were given morphine $10 \mathrm{mg}$ intramusoularly. The frequency of administration of these drugs was at the discretion of the nursing staff. Twenty-four hours after operation the patients were questioned regarding unusual experiences since the operation, particularly whether they had seen, heard, or felt anything that seemed 